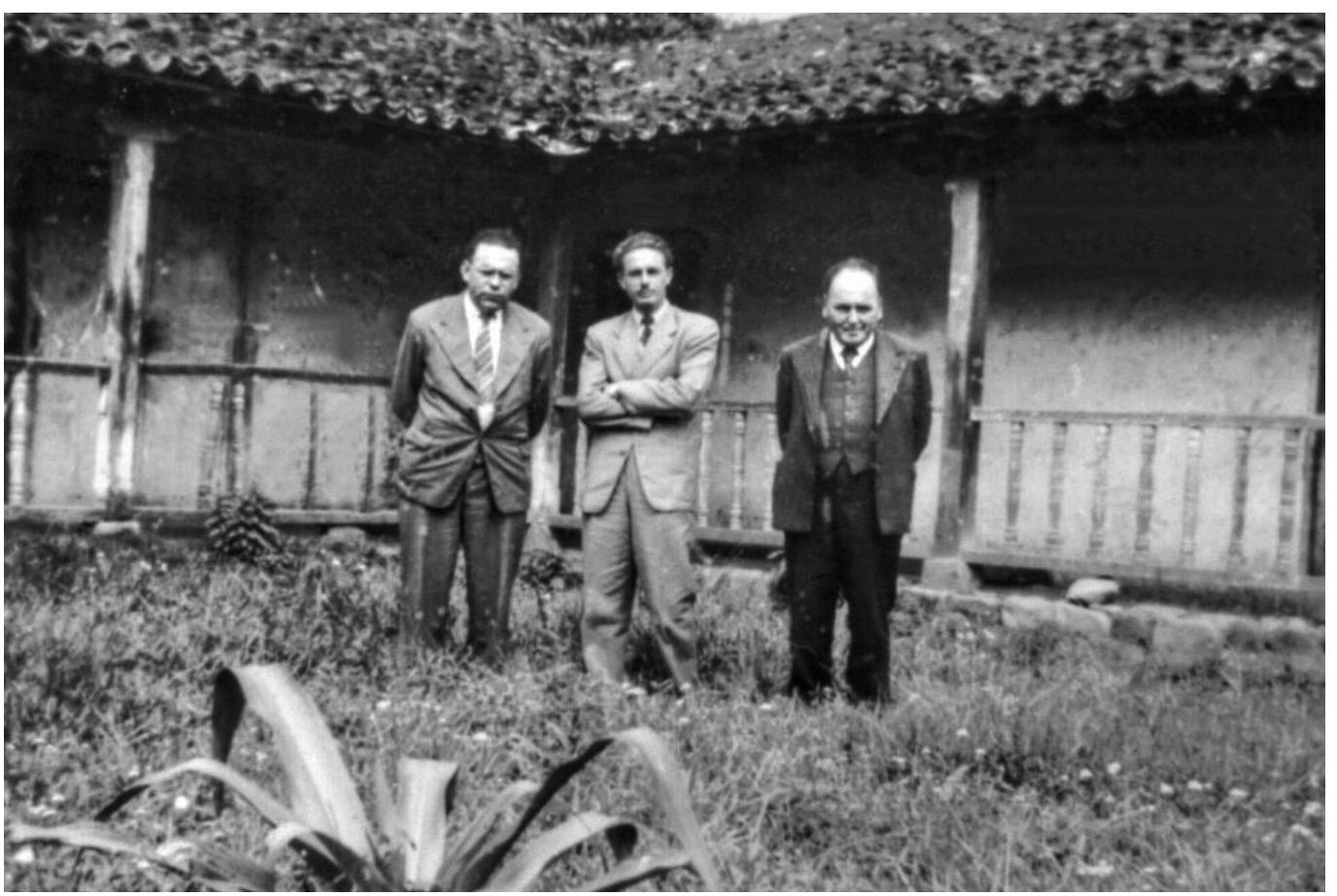

Foto del archivo personal de Manuel Mora Salas 


\title{
Exilio comunista costarricense en México 1940-1950: el caso de Manuel Mora Valverde
}

\section{Costa Rican communist exile in Mexico 1940-1950: The case of Manuel Mora Valverde}

\author{
German Chacón Araya \\ Instituto de Estudios Latinoamericanos (IDELA) \\ Universidad Nacional, Costa Rica \\ german.chacon.araya@una.cr
}

\begin{abstract}
Resumen
Manuel Mora Valverde fue un destacado político costarricense, líder del Partido Comunista y de Vanguardia Popular. Su participación fue esencial en dos grandes momentos de la historia contemporánea de Costa Rica: la alianza entre la Iglesia Católica y el gobierno republicano de Calderón Guardia para la creación de las garantías sociales, y la firma del Pacto de Ochomogo con el líder socialdemócrata José Figueres Ferrer. Sin embargo sufrió el exilio como resultado de los acontecimientos políticos de la década de 1940.
\end{abstract}

Palabras claves: ideas de Manuel Mora Valverde, Partido Comunista de Costa Rica, luchas sociales, comunismo "a la tica"

\begin{abstract}
Manuel Mora Valverde was an outstanding Costa Rican politician, leader of the Communist Party and Popular Vanguard Party. His participation was very important during two events of contemporary Costa Rican history: the alliance with the Catholic Church and the republican government of Calderón Guardia for the creation of social warranties, and also the signature of Ochomogo Agreement with the social-democratic leader José Figueres Ferrer. However, Mora was the victim of exile as a result of political events in 1940 decade.
\end{abstract}

Keywords: Manuel Mora Valverde and his ideas, Communist Party of Costa Rican, social fights, Costa Rican style communism 
$\mathbf{E}$ n los años 70, tuve la dicha de conocer al fundador del Partido Comunista de Costa Rica, el benemérito de la patria y gestor del Pacto de Ochomogo, Manuel Mora Valverde. Con él compartí muchas horas de ricas e inolvidables conversaciones que se daban en medio de la lucha política. A veces en su estudio privado o durante viajes al exterior, en que se me asignó la honrosa misión de garantizar su seguridad personal. Esta cercanía ha sido una ventaja para estudiar a este personaje.

Como acompañante, visité diferentes lugares donde se reunían don José Figueres Ferrer y Manuel Mora, para analizar la situación nacional e internacional y buscar salidas a diversas y complejas situaciones de la coyuntura político-militar de entonces. Manejaban temas como la búsqueda de la unidad del FSLN, la caída de Somoza, o la paz centroamericana, para mencionar unos pocos aspectos de esas tertulias. Ese contacto debe servir para visualizar desde otra óptica mucho de lo acontecido y que trato de recoger en estas líneas.

Para poder entender un poco a nuestro personaje debemos hacer una ubicación temporal que parte de la fundación del Partido Comunista de Costa Rica el 16 de junio de 1931, acto que llevará a una manera diferente de hacer política: su objetivo era buscar la transformación de la sociedad y la instauración del socialismo. Estas afirmaciones van ir generando la confrontación propia de un partido clasista con la burguesía, como se puede leer en las actas del Congreso de la República durante la décadas siguientes.
Veamos cómo se planteaba la lucha de clases en esos días: Vote por una municipalidad exclusivamente de los trabajadores; por una Municipalidad que no gaste dinero en adornar los barrios ricos, sino en sanear los barrios pobres. Vote por el Bloque Obrero Campesino. (Trabajo, 1932:2).

En 1932, el Partido Comunista, con el nombre Bloque de Obreros y Campesinos, participa por primera vez en unas elecciones, eligiendo a dos regidores municipales. Dos años después, el Partido Comunista elegía dos diputados al Congreso Nacional (hoy Asamblea Legislativa); uno de ellos fue Mora Valverde.

En el programa del Partido Comunista de Costa Rica se expresan los conceptos fundamentales acerca de su noción de sociedad, del papel del proletariado en ella y del sistema social que eliminará la explotación del "hombre por el hombre". Fija con precisión las tareas políticas y señala las pretensiones más inmediatas, que son las que deben determinar el contenido de la labor de agitación parcial a favor de pequeñas reivindicaciones, como aparecen acopiadas en las hojas sueltas, en los programas electorales, en el periódico Trabajo y en los discursos de Manuel Mora.

En 1933, para llamar la atención sobre la difícil situación de los trabajadores, fustigados por la desocupación y el hambre, organizó un gran movimiento de los desocupados. Se realizaron masivas manifestaciones, entre las que se destaca la del $1^{\circ}$ de mayo de 1933, así como la llevada a cabo a fines de ese mismo mes, que concluyó con sangrientos enfrentamientos con la policía. En 1934, el Partido Comunista 
organizó la lucha de los obreros bananeros del Atlántico, los cuales vivían en condiciones miserables, denunciadas en el periódico Trabajo. Esta lucha trajo como resultado la Huelga Bananera del 34, en la que tomaron parte más de 10000 obreros. Esta confrontación de clase elevó la conciencia del pueblo, abrió camino para el desarrollo del movimiento sindical y enalteció el prestigio e influencia del Partido Comunista y de sus dirigentes principales en ese momento: Carlos Luis Fallas y Manuel Mora Valverde.

Las protestas de los trabajadores bananeros y las frecuentes movilizaciones desembocaron a partir del 9 de agosto de 1934, con la conducción del Partido Comunista, en lo que se conoce como la gran Huelga Bananera de 1934. Dicha huelga fue el movimiento social más importante del año 1934, pero no el único.

En efecto, a lo largo de aquel año hubo protestas, paros y huelgas de los diversos sectores laborales del país, los zapateros, los sastres, los panaderos, los tipógrafos, lo obreros agrícolas, etc. También en ese año los peones y medianos productores cafetaleros estaban enfrascados en una ruda batalla contra los beneficiadores, para elevar el precio de su producción. (Rojas, 1989:72)

La realización del VII Congreso de la Internacional Comunista ${ }^{1}$, celebrado en 1935 en Moscú, marcaría el camino por donde discurriría el quehacer de los partidos comunistas y de los movimientos populares.

1 En 1935 el partido se hizo representar en el VII Congreso de la Internacional Comunista, celebrado en Moscú, con el dirigente obrero Rodolfo Guzmán ... (De la Cruz, 1980:05)
El análisis efectuado fue profundo y se pudo establecer el riesgo que significaba para la humanidad el nazismo-fascismo. Esta coyuntura permitió a Manuel Mora fortalecer su lucha contra el fascismo "imperialismo" y desarrollar un discurso sobre la política de alianzas, que marcó el devenir por donde hubo de transcurrir la construcción del Estado costarricense.

Manuel Mora Valverde fue un pensador adelantado a su época, político destacado, luchador social, diputado combatiente, periodista agitador de conciencias, orador de barricada y exiliado.

En 1938, Manuel Mora propone la tesis el "comunismo a la tica", cimentado en los principios del marxismo-leninismo, en una interpretación apropiada de la realidad nacional y en un programa de transformación social para la Costa Rica de los años 30 y 40 del siglo pasado. Fue consecuente con los planteamientos teóricos de Carlos Marx. El "comunismo a la tica" tiene su origen en una concepción que vincula la lucha social y política con el propósito de elevar los estados de la conciencia de clase de las masas populares y de impulsar transformaciones en la institucionalidad en beneficio de las colectividades de acuerdo con las condiciones socioeconómicas existentes.

Entendido en aquel momento como una especie de transición democrática al socialismo o de etapa democrática de la revolución. Pensamiento avanzado para su época, como destacaba el diputado José Merino del Río en el debate legislativo donde Manuel Mora Valverde fue declarado Benemérito de la Patria: 
Trató de hacer (...) una síntesis creativa y por eso lanza en Costa Rica la tesis de que aquí se podría aplicar un comunismo que él denominó "a la tica", cincuenta años antes de que en Europa surgieran corrientes novedosas como el eurocomunismo, por ejemplo, que trataban de combinar la idea del socialismo con la idea de la democracia. En este pequeño país hubo un hombre talentoso que planteó la posibilidad de que en Costa Rica se pudiera combinar el ideal socialista con el ideal democrático, el ideal de la libertad, con el ideal de la igualdad y de la justicia social.

El "comunismo a la tica" construyó en aquellos tiempos instrumentos políticos partidarios firmes en sus principios $\mathrm{y}$, al mismo tiempo, flexibles en sus tácticas y sus políticas de alianzas. Como antecedentes inmediatos están la Liga Antiimperialista de las Américas (Sección Costa Rica) y la Asociación Revolucionaria de Cultura Obrera (ARCO). Ya como agrupaciones político-ideológicas permanentes, el Partido Comunista de Costa Rica, el Bloque de Obreros y Campesinos (como instrumento electoral), el Partido Vanguardia Popular y, como coalición, el Bloque de la Victoria.

Uno de estos instrumentos fue la política de alianzas para lo cual estableció un proceso con diferentes actores, dentro de ellos el Dr. Rafael Ángel Calderón Guardia y Monseñor Víctor Manuel Sanabria, con el Partido Republicano y la Iglesia Católica respectivamente, y el surgimiento de Vanguardia Popular fue una muestra de realismo y audacia política. Se había disuelto la Comintern, la Tercera Internacional Comunista, y eso creó condiciones para el encuentro, comprensión y constitución de esta alianza original en la historia política del Continente. Como lo expuso el ex diputado José Merino del Río en el plenario:

...Por primera vez un líder comunista hace una alianza con el jefe de una Iglesia Católica nacional y con el Presidente de un Ejecutivo que no compartía las ideas de Mora, pero que supieron esas tres personalidades, el doctor Calderón Guardia, Monseñor Sanabria y Manuel Mora Valverde, poner por encima de sus diferencias ideológicas, y por encima de sus visiones también diferentes sobre diversos aspectos de la vida social y política del país, por encima de sus discrepancias pudieron poner todo al servicio de la unidad de propósitos, para hacer posible en esos años la reforma social más importante de la historia política nacional, la reforma social que hoy sigue siendo la base de la conciliación nacional; sigue siendo la base del derecho y de la justicia...

Un día después de la disolución del Partido Comunista, ocurrida el 13 de junio de 1943, Manuel Mora Valverde le escribe a Monseñor Sanabria para informarle de la constitución de un nuevo partido denominado Vanguardia Popular y le plantea que:

...Urge crear un bloque poderoso de todas las fuerzas nacionales progresistas que sean capaces de entender que se imponen grandes sacrificios para poder salvar a Costa Rica.

A su vez, Monseñor Sanabria responde de inmediato:

Juzgo que en el Programa del nuevo partido o agrupación, tal como consta en el texto que he recibido, de una parte quedan a salvo, aunque en forma 
negativa, las doctrinas fundamentales que informan la conciencia católica, y positivamente no hay nada que desnaturalice o desmejore aquellas doctrinas fundamentales, y por consiguiente sin gravamen de conciencia pueden los católicos que así lo deseen, suscribirlo e ingresar en la nueva agrupación... (Citado por Villalta, 2018)

En el año 1939, seguía el debate en la asamblea legislativa y para ese entonces Manuel Mora se refería a las contradicciones con los sectores oligárquicos en los siguientes términos:

Hay interés en atacarnos, en agredirnos a todo trance, en abrir en Costa Rica una lucha que no tiene razón de ser. Pues vamos a ella. Y que el país vea claro: nosotros no la estamos provocando. Hemos luchado y lucharemos dentro de los marcos de la ley. Pero sí nos defenderemos. Y nos defenderemos, porque tenemos convicciones enraizadas en lo más profundo de nuestras almas; porque creemos sinceramente en la bondad de nuestros principios políticos y económicos. Ni con leyes mordaza, ni con encarcelamientos, ni con ninguna otra clase de medidas se nos va a impedir predicar en el país el ideario que sustentamos. Y triunfaremos al final de la jornada. Porque representamos la Historia en marcha; porque representamos el porvenir, porque representamos la verdadera civilización. Vosotros los que nos adversáis, sois el pasado, la retrohistoria, el absolutismo, la mentira social. (Mora, 1980:38)

...veamos nuestra política obrera. Pedimos por ejemplo el alza del salario mínimo, pero tomando de antemano las disposiciones necesarias para que esa alza no sea arruinadora para los pequeños finqueros ni para los pequeños patrones del país. En las mismas condiciones, pedimos la modificación de la Ley de Accidentes de Trabajo, para que esta ley cubra también a los trabajadores del campo... luchar por la efectividad de la jornada de ocho horas en la industria y en la agricultura en general y de seis horas para el trabajo nocturno y el que se realiza en medios insalubres... Pedimos una legislación completa, protectora de la mujer trabajadora y de los menores de edad... (Mora, 1938:102),"

Se inicia una nueva etapa en la vida institucional del país. Se da una revolución jurídica sin sangre, aunque sí con lágrimas, de los sectores sociales asalariados por el advenimiento de la Justicia Social con "pan y libertad". La obra del PC y de don Manuel Mora fue un esfuerzo compartido y sin mezquindades con el doctor Calderón Guardia, con la Iglesia Católica y con el pueblo. En la apertura de la segunda gestión se va a producir un viraje de 180 grados en la posición política del presidente Calderón, que según palabras de Manuel Mora:

...ocurre como resultado de un golpe de Estado en ciernes, lo que obliga a su hermano Francisco Calderón, a buscar al líder comunista Manuel Mora para explicarle la situación; Manuel evaluó la situación interna y externa, diciéndole a Calderón que "si él estaba en disposición de luchar por mejorar las condiciones del pueblo, él y su partido estarían ahí para defender la institucionalidad.

2 Incorporados en la Constitución Politica en el año 1943, en el capítulo de garantías Sociales, código de trabajo, en donde se incorpora la Ley de Riesgos Profesionales 
De esta manera, tendió los puentes necesarios para establecer un proyecto país, donde lo social ocuparía el lugar principal, dando como resultado la aprobación de una plataforma programática mínima con el calderonismo que, en resumen, buscaba:

1. Promover la reforma de la Constitución Política, incorporándole el capítulo de las Garantías Sociales.

2. Promulgar el Código de Trabajo.

3. Crear la Caja Costarricense de Seguro Social.

A partir de ese momento, se abrió uno de los capítulos de mayor relevancia en la historia de Costa Rica, que va fijar el norte por donde habría de transitar la construcción del nuevo Estado costarricense, lo que llevaría a la creación de instituciones y legislación particulares, promotoras de una mejor calidad de vida. Para ello, se parte de un ideal de Estado social, en el que se garantice una mejor calidad de vida para los habitantes de la nación y una institucionalidad menos clientelar, sobre todo en el nombramiento de servidores públicos (creación del Servicio Civil).

Dentro de este marco conceptual, la alianza se fortalece y permite alcanzar los frutos esperados por Mora, culminando con la creación de la Caja Costarricense de Seguro Social, el Código de Trabajo y las Garantías Sociales, que fueron proyectos desarrollados por Manuel Mora Valverde y su partido, compartidos ideológicamente por sectores avanzados de la Iglesia Católica y, finalmente, llevados a cabo por el gobierno de Calderón Guardia. Estos proyectos cambiaron la institucionalidad y se convirtieron en la más profunda modificación a la Constitución de 1871; transformación ideológica que va a incidir en el tipo de Estado, y en consecuencia, afectará la forma de gobernar.

Mora justificó la política de alianzas del Partido a partir de tres ejes principales: defensa de las libertades democráticas, programa de reformas económico-sociales y defensa de los intereses nacionales frente al imperialismo.

Las conquistas de esta alianza política se vieron amenazadas cuando el gobierno de Calderón Guardia comenzó a perder el apoyo de los sectores agroexportadores y financieros, que vieron la reforma social como una amenaza a sus intereses; esto ligado a la declaratoria de guerra al llamado Tercer Eje, y la pretensión de los hermanos Calderón de permanecer en el poder por medio de su candidato Teodoro Picado, desencadenaron, posteriormente, la Guerra Civil de 1948.

En la revista Trabajo, del 11 de septiembre de 1943, aparece una de las definiciones más completas respecto al concepto de democracia que escribió Manuel Mora:

La democracia no es un estado social estático sino dinámico, es precisamente aquel estado político social que más ampliamente se presta, por esencia, para el progreso del bienestar y del decoro humano. Frente al fascismo, frente al nazismo, frente al imperialismo, la democracia actual proclama la liberación de las clases trabajadoras, incorporando sus derechos vitales y culturales a los derechos puramente políticos e individuales... (Mora, 1943:4) 
Manuel Mora se expresaba, en 1947, al analizar el avance del proyecto político revolucionario de los comunistas costarricenses, de la siguiente forma:

...estamos viviendo en una revolución, no en el sentido vulgar. Antiguamente nuestra clase entendía por esta palabra el motín. Nosotros entendemos por ella el cambio; el quebrantamiento de intereses creados; la creación de instituciones nuevas; la marcha hacia la justicia social; eso entendemos por revolución. Dijimos al patrón: Usted tiene derecho a la prosperidad, pero no a que ella vaya en perjuicio del pueblo. El Estado le protege a usted, pero debe proteger también al trabajador. Dijimos al terrateniente: La propiedad no habrá de ser ya la cosa absoluta que era en el pasado. Sólo puede usted mantener su riqueza teniendo en cuenta las limitaciones que impone el interés social; $\mathrm{y}$ esto no lo logran entender muchos terratenientes ignorantes... Hemos hecho una revolución y queremos llevarla adelante. (Mora, 1980: 204 y 207)

Sin embargo en la coyuntura que supone la Segunda Guerra Mundial posterior al ataque a Pearl Harbor, el Gobierno de Calderón ${ }^{3}$ declaró la guerra a Alemania y a Japón, antes de que lo hicieran los Estados Unidos en el año 1941. En este período se denunciaron violaciones a los Derechos Humanos de la población alemana, italiana y japonesa por parte del gobierno.

Uno de los deportados fue José Figueres en el año 1942 rumbo a México, después de pronunciar un discurso contra el gobierno de Calderón Guardia. Figueres aprovechó

3 Médico y político costarricense, ocupó la Presidencia de la República entre 1940 y 1944. su estadía en la república mexicana para hacer contactos con el presidente de Guatemala, viajó a los Estados Unidos y se reunió con grupos centroamericanos y caribeños que conoceremos como la Legión Caribe. Regresó en 1944 con un plan para quitar a los Caldero- Comunistas del poder y derrocar algunos gobiernos del área, según los expone Aguilar (2014).

Bell nos plantea: "Figueres regresó del exilio el 23 [sic: 21] de mayo de $1944 \ldots$ hizo un discurso desde el balcón del Diario de Costa Rica... en el cual atacó a Calderón Guardia y se lamentó del estado de 'deshonra y pobreza' en que había encontrado a Costa Rica". Y agregaría: "A la violencia había que responder con la violencia... Pidió a los costarricenses que recordaran las glorias de 1856 y $1918 \ldots$ Dijo que había valor en las discusiones políticas, pero mantuvo que la acción política no llevaría a una transferencia del poder. Creía que el único veredicto que las fuerzas gubernamentales reconocerían era de naturaleza militar".

Así, Bell fue el primer investigador que reconoció un proceso fundamental en la construcción de la violencia que llevó a la Guerra Civil de 1948: la fortificación de un grupo que estaba dispuesto a rechazar la política y a cambiarla por armas que permitieran llevar adelante una revolución.

Bell añadió que el plan de Figueres era trabajar en varios niveles, entre ellos: mantener la actividad política, pero en "toda ocasión oportuna, se debía adoctrinar a la Oposición sobre la futilidad de las elecciones, y orientarla a asociar la idea de revolución con la figura de Figueres". Además: "Hacia octubre de 1946, Acción 
Demócrata sugirió un nuevo lema: Elecciones no, Rebelión sí”. (Díaz, 2014)

La reacción contra nosotros no se hizo esperar decía Manuel Mora: "La misma potencia a que acabo de referirme (Estados Unidos) pretendió, ya siendo Presidente el Lic. Picado, que los cinco Gobiernos de Centro América se comprometieran, mediante convenio secreto, a poner fuera de Ley al comunismo en todo el istmo centroamericano. Cuando el documento llegó a manos del Presidente de Costa Rica ya venía firmado por Somoza, Carías y Castañeda Castro. No lo había firmado Arévalo. Tampoco lo firmó Picado".

\section{Y sigue explicando Mora:}

Don Otilio fue invitado a visitar los Estados Unidos, también por aquellos mismos días. En Washington fue alojado en Blair House. Cuando regresó a Costa Rica todavía con el polvo del camino pegado a la suela de sus zapatos hizo que un grupo de diputados cortesistas le firmara un documento que era una demanda al Presidente de la República para que pusiera fuera de Ley al Partido Vanguardia Popular. Hasta aquel día no se había atrevido a enderezar semejante ataque contra sus antiguos aliados y amigos. Probablemente le ha de haber costado mucho esfuerzo vencer sus últimos escrúpulos de viejo liberal. Pero los venció.

Como era lógico, el señor Picado se negó a ponernos fuera de ley. Ulate, seguramente, ganó buenas indulgencias en Washington.

Pero exactamente un mes después de que el Gobierno de Picado cayó, fuimos ilegalizados; y desde entonces, quien más se ha empeñado en que se mantenga nuestra ilegalidad es el señor Ulate. Tampoco parecen casuales todas estas cosas ni simplemente atribuibles las maniobras de política de campanario. (Mora, 1980: 235-236)

En 1948, aparece en el escenario la Guerra Civil. Manuel Mora expresa en el seno del Comité Central con la firmeza que le caracterizaba "que no debería irse a la guerra, que se habría alcanzado una importante cantidad de diputados cerca de nueve escaños". También votó en contra de que se anularan las elecciones; solo Jaime Lobo y él así lo hicieron; expresó en esa reunión del Comité Central de su Partido Vanguardia Popular, que anular las elecciones probablemente generaría una gran tragedia que después lastimosamente se vino a corroborar.

En palabras de Manuel:

Nosotros hicimos resistencia a la capitulación durante algunos días, porque, francamente, no lográbamos entenderla. No comprendíamos por qué había necesidad de capitular siendo Figueres más débil que nosotros. Sin embargo, muy pronto comprendimos la argumentación del señor Presidente, porque nos invadió la Guardia Nacional de Nicaragua con el pretexto de que venía a salvar a Costa Rica y a Centroamérica del comunismo. También supimos que otras fuerzas extranjeras también estaban listas para cruzar nuestras fronteras. Tuvimos que aceptar la capitulación del señor Picado. Así, evitamos que nuestra Patria fuera ocupada por ejércitos de otros países.

Según lo manifiestan sus más cercanos seguidores, durante la Guerra Civil se 
resistió con valentía, con coraje político y cuando vio que esa guerra rompía el tejido social costarricense y advertía que se daría un mayor derramamiento de sangre, y que ponía en juego la soberanía ante los movimientos de tropas extranjeras en las dos fronteras terrestres y el abandono de los "aliados", Manuel Mora tuvo el coraje imperioso para buscar la paz.

En 1948, fue el principal artífice del fin de las hostilidades, según sus propias palabras. Estos hechos se dieron bajo las siguientes consideraciones:

Yo subí al Alto de Ochomogo a hablar con Figueres cuando ya don Teodoro había capitulado y en momentos en que el país estaba invadido por la Guardia Nacional de Somoza. Figueres se había negado a venir a la Embajada de México y yo decidí buscarlo en su propio terreno. Le expliqué que el país se encontraba invadido bajo el pretexto de que los comunistas nos negábamos a aceptar la capitulación de Picado. Le agregué que nuestro Partido no se desarmaría hasta tanto él no nos firmara un pliego de garantías políticas y sociales ya que las garantías de vidas y haciendas obtenidas por el Cuerpo Diplomático no bastaban. Figueres aceptó mis condiciones, las cuales, al día siguiente, fueron incorporadas al Pacto de la Embajada de México. (Mora1980: 239)

El encuentro se dio día 17 de abril de 1948 en el Alto de Ochomogo, muy entrada la noche. Los comunistas viajan en un Jeep conducido por un miliciano, en el cual iban Manuel Mora Valverde, secretario general del Partido Vanguardia Popular (PVP) y
Carlos Luis Fallas Sibaja ${ }^{4}$, comandante de las Milicias Comunistas quienes se hicieron las señas convenidas y al grupo se unió José Figueres Ferrer, comandante del denominado Ejército de Liberación, y con presencia testimonial del Pbro. Benjamín Núñez Vargas, capellán del ejército figuerista. Se reunieron y convinieron en firmar el "Pacto de Ochomogo" que significó el desarme de los combatientes obreros, artesanos y campesinos vanguardistas a cambio de algunas garantías.

En síntesis, el compromiso de José Figueres era garantizar la vigencia del Código de Trabajo y el sistema de seguridad social, no producir acciones represivas contra el Partido Vanguardia Popular, sus militantes, familias y organizaciones. Pero esos compromisos fueron truncados por la Junta de Gobierno y los miembros de la Constituyente, que aprobaron en la Constitución de 1949 incluir el Segundo párrafo del Art. 98, mediante el cual se proscribió al Partido Comunista, lo que le obligó a actuar al margen como una organización clandestina, hasta la modificación de este artículo en el año 1975.

4 Durante los hechos políticos de 1948, como el mismo Calufa lo cuenta en su autobiografía, se improvisó como jefe militar de la heroica Columna liniera. Esta marchó desde la zona sur hasta Cartago, participó como testigo de facto, en las sombras de la noche, acompañando a Manuel Mora, al Alto de Ochomogo. Mi labor literaria es muy escasa, porque la mayor parte de mi tiempo lo dedico a la lucha por la total liberación de mi pequeña patria. En 1940 escribí Mamita Yunai, publicada en Costa Rica en 1941, y que pasó desapercibida por años, hasta que el soplo poderoso del gran poeta Pablo Neruda la echó a correr por el mundo. En 1947 publiqué la novela Gentes y Gentecillas, en una pésima edición que corregí luego pero que no he podido volver a editar. Ese mismo año escribí una novela y unos cuentos cortos, que me fueron robados y destruidos durante la represión de 1948. En 1952 publiqué Marcos Ramírez. 
En palabras de Manuel Mora: "en abril de 1948 ingresó don José Figueres Ferrer a la ciudad de Cartago, se dice que con aproximadamente 800 hombres, la mayor parte de estos eran extranjeros. El Gobierno tenía sobre las armas, en San José, unos cuatro mil hombres más. Esa era la correlación de fuerzas: 5 mil hombres con todos los recursos del Gobierno, rodeando a 800. En esas condiciones, y sin que el señor Figueres se hubiera movido todavía de Cartago, don Teodoro Picado capituló. En una carta que nos entregó al Dr. Calderón Guardia y a mí nos explicaba, que "fuerzas incontrastables" lo habían obligado a capitular; y que lo había hecho para evitarle al país una gran humillación. Esta carta fue publicada por el señor Picado en un folleto hace pocos años, Figueres entró a la capital; y las mismas fuerzas que habían obligado a don Teodoro a capitular le ordenaron a Figueres entregarle el Poder al señor Ulate. Don José hizo toda clase de concesiones para mantenerse en el Gobierno: entre otras, la contratación petrolera, nuestra ilegalización y el desconocimiento del Pacto de Ochomogo. Pero tuvo que terminar aceptando una transacción. De acuerdo con esta transacción le entregó el Poder a Ulate un año y medio después.

No le fue posible sostenerse por más tiempo en ese periodo. Parece que tampoco fue casual esta notable colaboración que Washington le dio a don Otilio".

La salida de Manuel Mora hacia México es explicada en carta fechada 24 de abril al embajador Carlos Ojeda, donde sostiene que las autoridades costarricenses no le garantizan la vida, y pide el asilo en esa embajada por el tiempo necesario para definir su situación.

Ojeda comunica al secretario de relaciones exteriores Gonzalo Facio de la permanencia de Mora en su embajada y expresa su solicitud y aceptación de asilo. El 29 de abril, Gonzalo Facio señala: "que esta secretaria de Estado se halla en un todo conforme con la salida del país de las personas que se han acogido a esa Honorable Embajada, con motivo de los últimos acontecimientos políticos recientemente ocurridos, con garantías absolutas de sus vidas, desde luego, por parte del actual Gobierno de la República..."

Cinco días después tomaba un avión que le conduce a México. No sin antes agradecer al embajador la hospitalidad recibida. Quien lo acompaña hasta el propio aeropuerto ubicado en aquel entonces en La Sabana. La salida de Mora de San José fue dramática, en sala de espera fue acompañado por el obispo Víctor Manuel Sanabria para resguardar su vida, aun así, sufre un último atentado antes de subir al avión "escoltado de policías, en el final de la pista, un grupo de excombatientes ametralló el avión al extremo de que en vez de dirigirse a México, cambió su destino original hacía Panamá." Decía Manuel: "Cuando a mí se me expulsó del país, el FBI cuyo jefe es otro Hoover al pasar yo por Panamá, donde el coronel Remón me mantuvo preso, se apoderó de todos los documentos privados que llevaba en una cartera y los fotografió. Esas fotografías le fueron entregadas rápidamente al señor Ulate y no a la Junta de Gobierno. Don Otilio, con orgullo y regocijo, usó muy pronto algunos de ellos, aunque a su manera, es decir, adulterándolos." 
Entre esos documentos había "una carta que yo había dirigido al presbítero Núñez en 1947", dándole las gracias por un cuadro que me había obsequiado. Entre otras cosas pedía yo al señor Núñez en dicha carta que me saludara a "nuestro amigo común": me refería claramente a Monseñor Sanabria. Pues bien, Ulate la publicó hace algún tiempo, pero le dijo al país que aquel saludo mío era para el señor Figueres y no para Monseñor. ¡Esa es su probidad periodística!"

Es evidente que Costa Rica había entrado en una etapa muy negra para la democracia; como vemos, el párrafo segundo del artículo 98 de la Constitución de 19495, es contrario a toda convivencia pacífica y raya con cualquier interpretación de un régimen democrático y representativo; por el contrario, se trata de una imposición y límites de tono dictatorial para ejercer con toda la fuerza de la ley en contra de los opositores del Gobierno.

Significativo resulta de estas medidas que el PVP queda declarado fuera de la ley, sus máximos dirigentes expuestos ante esta medida extrema expulsados del país, detenidos, sacados de sus casas delante de sus familias y llevados en vehículos militares a la Penitenciaría Central y otros lugares similares por toda la geografía nacional. Ellos son: Arnoldo Ferreto Segura, Adolfo Braña Roza, Carlos Luis Sáenz Elizondo, Manuel Moscoa Barrantes, Luis Carba1lo Corrales, Rodolfo Guzmán Rodríguez, Enrique Conde Conde, Fernando Chaves

5 Debe recordarse que, como consecuencia de la guerra civil de 1948, el párrafo segundo del artículo 98 de la Constitución Política prohibía la formación o funcionamiento de partidos "antidemocráticos", a juicio de la Asamblea Legislativa (Salazar y Salazar, 1992)
Molina, Carlos Escalante Vega, Álvaro Montero Vega, Víctor Cordero Segura, Jaime Cerdas Mora, Carlos Luis Fallas Sibaja, Federico Picado Sáenz, Ricardo Pérez Méndez, Rigoberto Álvarez Maroto, Luis González González y Pilar Bolaños. A estos nombres se agregan una treintena de personas que fueron arrestadas o llamaron para interrogatorios y acusados de sedición.

En el periódico clandestino Trabajo correspondiente a julio de $1948, n^{\circ} 6$, se pública un extracto del recurso de inconstitucionalidad del decreto elaborado por Jaime Cerdas y demás dirigentes comunistas que se encontraban en la cárcel: "...el Tribunal de Sanciones inmediatas es un organismo integrado y organizado por facciosos de los que detentan el poder, creado exclusivamente como reza, cínicamente el propio decreto ley que le dio nacimiento,-para perseguir a los llamados caldero-comunistas, con motivo de las quejas de los que antes fueron llamados oposicionistas y hoy son oficialistas. Es un Tribunal Especial, para determinadas causas, de un partido para perseguir a otro partido; no de jueces sino de verdugos. Es un tribunal contrario a la Constitución, vigente en parte, y contrario a todas las tradiciones de nuestra república".

El decreto era contradictorio con la legislación vigentes viola las garantías nacionales individuales que la Constitución establece en varios de sus pasajes, como el principio de que "todo hombre es igual ante la ley", pero los caldero-comunistas son desiguales al crearse un tribunal especial y no tribunales comunes. Era un decreto que se aplicaba retroactivamente, y el otro argumento es que la constitución establece el derecho de reunión para 
ocuparse de asuntos políticos sin censura. Por tanto, se impugna el decreto por inconstitucional que los convierte en reos y acusados de sedición"....

La persecución y el encierro a la actividad de la movilización social estrecha el cerco de libertades de los sectores populares durante el gobierno de Otilio Ulate, así que poco cambiaron las cosas. Este marco de legalidad de la violencia permite a los vencedores actuar con toda impunidad sobre los bienes y las personas, sucediéndose uno tras otro atropello y violación de los derechos más elementales de la ciudadanía ahora etiquetada por sus ideales o preferencias políticas. Se crean los tribunales de sanciones inmediatas y los tribunales de probidad para perseguir y condenar sin escrúpulos a los ciudadanos; del mismo modo operan los Tribunales de Probidad que pretendían investigar defraudaciones al fisco y el reintegro de las sumas de dinero de tales defraudaciones a la hacienda pública. Muchos ciudadanos y familias fueron despojados de sus bienes y confiscadas sus cuentas, principalmente calderonistas.

En uno de tantos expedientes que se abrieron durante el año 48, Francisco de Paula Amador Sibaja, quien era agente fiscal, expone que se cometieron actos como saqueos, merodeo (hurto de ganado, café, leche en gran escala), homicidios, torturas, flagelaciones, ultrajes, en daño de la ciudadanía oposicionista y de mujeres y niños. $\mathrm{Y}$ agrega que es innegable la participación criminal en el desarrollo y producción de los hechos arriba descritos, de los señores Calderón, Rafael y Francisco. Manuel Mora Valverde, René Picado, Juan Tavío, Manuel Rodríguez Torra (sic), Federico
Volio González, Alfredo Garrido Conejo, Rodrigo Perera, Julio López Masegosa y de todos aquellos que como consecuencia de las investigaciones resulten responsables.

En consecuencia, este grupo de comunistas decide en primera instancia quedarse en el país, dejando la posibilidad del destierro y el exilio para aquellos que consideren que esa es la vía, esto último limitado a sus propias posibilidades y sin el apoyo o ayuda oficial.

La carta anteriormente transcrita fue solamente publicada por el periódico clandestino Trabajo, en su edición $n^{\circ} 5$ de julio de 1948. De manera premonitoria, de ese mismo periódico, en la nota "El camino del crimen", se lee qué va ocurrir con los comunistas en su futuro inmediato: "Ante la negativa de los dirigentes vanguardistas a abandonar por las buenas el país, tres caminos le quedan según La Nación del 13 de julio de 1948, le queda al gobierno: el destierro forzoso, el encarcelamiento de por vida, o la libertad para esos presos políticos.

Un cuarto camino queda, que no menciona La Nación, pero al cual se refirió el Ministro de Justicia al enviar a nuestros camaradas un emisario con su mensaje de muerte: el Ejército Nacional los asesinará si no abandonan el país" ...(Chacón-Oliva, 2017).

Sería muy largo hablar de esta dolorosa etapa de la vida nacional, pero para aquellos que tengan interés en profundizar sobre el particular los invito a buscar la literatura que, han desarrollado investigadores como: Aguilar, Barahona, Chacón, Díaz, Molina y Oliva, entre otros, de los cuales he citado parte de sus publicaciones 
en este trabajo, a ellos gracias por su empeño para develar la verdadera historia, esa que apenas estamos conociendo.

Aunque, como lo hemos visto, Don Pepe, como le conocemos a José Figueres, y veremos a continuación, se habría planteado seguir actuando con los comunistas, tomándoles su parecer e integrándolos en la reconstrucción y modernización de la República, ¿qué o quién hizo que esas intenciones no se pudieran concretar?, porque la realidad fue muy distinta (Ver anexos).

La Nación del martes 17 de mayo de 1949, publica los mensajes cruzados entre Manuel Mora y José Figueres, provocados por la muerte de María Isabel Carvajal, que muestran las tensiones entre ambos, dejemos en extenso esta documentación que habla por sí sola. Mora escribe desde México el 14 de mayo de 1949:

"A José Figueres, casa presidencial.

Carmen Lyra ha muerto. Usted conocía muy bien y me conoce a mí. Su conciencia ha debido decirle siempre que ni ella ni yo somos autores de los crímenes que ha querido atribuirnos la propaganda perversa de los verdaderos enemigos del pueblo de Costa Rica. A pesar de eso, entiendo y acepto lo que se ha hecho y pueda hacerse contra mí, pero no puedo aceptar la iniquidad desplegada contra la mujer más noble y más valiosa que ha producido nuestro país. Iniquidad llevada al extremo de no permitirle pasar en su patria las últimas horas de su vida. Sobre su conciencia y sobre sus colaboradores gravitará siempre este crimen cometido en perjuicio de una persona ilustre ni de un partido, sino en perjuicio de una nación y de la cultura universal. MMV".
"San José, C.R. Mayo 16

Señor Manuel Mora

México D.F.

Comprendo que la exaltación de su ánimo, lógica en momentos para usted tan dolorosos, como los que debieron significar la muerte de una leal y abnegada colaboradora suya, lo haya determinado a imputarme un crimen que no cometí. La Junta de Gobierno que presido nunca negó a Carmen Lyra su ingreso al país y personalmente le indique, por conducto de Vicente Sáenz, de quien recibí gestiones directas en favor de ella, que no ponía objeción a su deseo de volver a Costa Rica. Pero que por el estado de emergencia que entonces vivía el país con motivo de la invasión, le aconsejaba, para su propia seguridad, no hacerlo inmediatamente. De las protestas de inocencia suyas, nada puedo decir, porque será la opinión pública ahora y mañana, y el juicio de la historia quienes viertan su verdadero veredicto. JF".

Como nos explica Mario Oliva: "Este cruce de cartas tan precisas y contundentes en acusaciones de uno y otro sobre un asunto tan delicado como fue la muerte de la escritora en México, y no en su país natal. Nos lleva a las siguientes consideraciones: En primer término dos posiciones en tensión al respecto, M.M.V., hizo esfuerzos y empeños de todo tipo para que Carmen Lira pudiese regresar en vida a Costa Rica, al punto de fraguar un viaje aéreo clandestino para transportar a Lira cuestión que no se produjo porque a Lira le alcanza la muerte, por su parte J.F. es contundente en cerrar las puertas a la escritora argumentando un motivo de inseguridad y la invasión, hoy sabemos que la escritora siempre tuvo su intención de retornar a su 
país antes de morir, en su última carta escrita desde ciudad de México fechada el 9 de marzo de 1949 (dos meses antes de su muerte) entre otras cosas expresa su deseo y añoranza de reunirse lo más pronto posible con sus seres más queridos.

El cierre de la nota de Figueres nos lleva a otro terreno más movedizo, dice el jefe de la junta de Gobierno, "de las protestas de inocencia de Mora", no lo exonera sino más bien lo envía a juicio esta vez al tribunal de la Historia con mayúscula, apela de este modo a una acepción de la historia como moral, como una especie de personaje mítico emitiendo sus propios juicios, con lo que se podría prescindir de todo tipo de análisis. Pasado más de medio siglo podría interpretarse basado en la historia que Mora fue absuelto y que Figueres por el contrario ha sido ubicado en su contexto como un personaje que no solo no dejó entrar a Carmen Lira en vida sino que actuó con mano fuerte y violenta contra sus adversarios políticos".

Manuel Mora Valverde, permaneció en México desde abril 1948 e intentó regresar en varias oportunidades; todo indica que no fue al menos hasta el año 1950 en el mes de marzo, que pudo hacerlo:

\footnotetext{
"No regresa Manuel Mora a su Patria confiado al azar o a una benevolencia de las autoridades de su país, sino que regresa por mandato de pueblo; por derecho propio de costarricense también por la urgencia de contribuir a salvar los intereses profundos de nuestros pueblos en esta hora difícil" (Lombardo Toledano, 1950).
}

Los intelectuales de América Latina, dentro de ellos Pablo Neruda, escriben una carta al señor Ulate con fecha 9 de marzo de 1950, dirigida a don Otilio Ulate Blanco, casa presidencial, San José: "como viejos admiradores del pueblo de Costa Rica y de sus tradicionales instituciones democráticas hemos visto con sincero pesar el eclipse que esas instituciones han venido sufriendo en los últimos dos años.

Sin embargo, el hecho de que Costa Rica haya retornado a la vida institucional y el de que usted, como Presidente de la República, haya manifestado su decisión de no apartarse de las normas democráticas para gobernar, hacen renacer nuestra esperanza de que esa nación vuelva a ser lo que fue: país respetuoso de los derechos individuales y colectivos de los ciudadanos.

Nos permitimos hacer estas manifestaciones con motivo del regreso a su patria del Lic. Manuel Mora Valverde, después de dos años de exilio en México. No dudamos que gozará de garantías bajo su gobierno, a pesar de los rumores que circulan sobre posibles atentados contra su vida. Saludan atentamente al señor Presidente.

Vicente Lombardo Toledano, Pablo Neruda, acompañan una veintena de firmas". (Citado por Chacón -Oliva, 2017). Señala M. Mora: "Pero en el mismo año en que llegó, después de que estallaran unas bombas en San José y sin que mediara ninguna investigación, Otilio Ulate como presidente, ordenó que se me hiciera preso... se me puso en una celda con los reos comunes... (Mora,1958), Mora es acorralado por unos delincuentes y debe intervenir José León 
Sánchez ${ }^{6}$, en salvaguarda de la integridad de Manuel, esto era lo que vivían los comunistas todos los días, los metían a la cárcel por horas y los volvían a la calle.

Don Pepe fue tratando de ir cumpliendo con los compromisos, llevó a cabo la nacionalización bancaria, la disolución del ejército, la creación del ICE, que terminó con la crisis de energía eléctrica que sufría el país, establecimiento de un impuesto sobre el capital, nacionalización de la producción y distribución de la hidroelectricidad, convocatoria de una Asamblea Nacional Constituyente que aprobó la Constitución Política que hoy nos rige, el fortalecimiento del Tribunal Supremo de Elecciones, el voto a la mujer, derogó la disposición legal que discriminaba a los ciudadanos negros. Además, la independencia del Poder Judicial y el Servicio Civil, Instituto Nacional de Vivienda y Urbanismo (INVU), creó la Universidad Nacional, que dará oportunidades a los hijos de obreros y a los pobres de la zona rural. Crea también el Instituto Tecnológico de Costa Rica (ITCR), entre otros.

Pero también debemos rescatar otra faceta donde Don Pepe y Manuel coincidieron en muchos espacios como nos lo permite ver la siguiente cita:

En la segunda semana de agosto de 1984, el ministro de seguridad pública Ángel Edmundo Solano concentra a la fuerza pública. José Figueres Ferrer llama a sus fuerzas de seguridad y sale hacia Panamá, Manuel Mora Valverde pone a segunda orden la Brigada Mora Cañas del partido, de lo cual es

6 Acusado de robarse la imagen de la Patrona de Costa Rica, la Virgen de los Ángeles. informado el ministro de seguridad y se hace un despliegue estratégico de los cuadros de la organización. Mientras tanto, "un grupo de empresarios y políticos se reúne en el hotel Cariari, uno de cuyos acuerdos fue dar un golpe de Estado a Luis Alberto Monge " (Salas, 1997: 325).

Es evidente que las contradicciones han estado presentes y los hechos demuestran que fueron los comunistas los más golpeados por el anticomunismo surgido de las acciones derivadas de la Guerra Fría a partir de los hechos armados de 1948 en Costa Rica, pero que ha sido parte del utillaje de la mentalidad de los sectores dominantes costarricense, a partir del andamiaje que propuso la ilegalización y persecución de los comunistas después del cese de hostilidades, como un recurso descalificador, que prevalece aún hoy y es parte del imaginario nacional, siendo empleado en el discurso oficial.

Ningún conflicto bélico en escala mayor puede evitar hechos duros e incluso crueles.

Para finalizar y ver lo difícil de la situación, veamos algunas narraciones recogidas en la década de los 80 en Costa Rica:

El Partido Comunista, y hablo específicamente de lo vivido en sus filas, sufrió muchísimo. Álvaro Montero, joven comunista que en esa época tenía escasos 22 años, relataba situaciones humanamente durísimas como el fusilamiento de decenas de jóvenes en Tejar del Guarco, uno de estos actos violentos fue lo vivido por Mario Zúñiga, a quien, en Puntarenas, colocaban sobre el pavimento caliente del medio día y luego lo pasaban a una 
marqueta de hielo hasta convulsionar. A Eduardo Mora le escuché relatos sobre las vigilancias de que fue objeto aquí en México de parte de la Legión Caribe o la defensa de la estación de radio del Partido cuando fue atacada y el secretario general del partido comunista, Manuel Mora hacía un discurso al país. O la narración que nos cuenta sobre el abandono irresponsable, para decir lo menos, por las fuerzas regulares del gobierno, de posiciones militares en la carretera interamericana. Para lo cual el Estado Mayor del PC tuvo que llenar esos vacíos en la línea de defensa, lanzado al combate, en condiciones en extremo difíciles, a la juventud comunista, con un costo muy elevado en vidas.

También recuerdo las palabras de Emilia Prieto y María Romero relatando los vejámenes de que fueron objeto, como raparlas y golpearle en sus partes íntimas y trasladarlas al Buen Pastor (cárcel de mujeres), por defender el ideal de construir una sociedad más justa, y sería interminable la lista de costarricenses que en el bananal o en las ciudades tuvimos oportunidad de conversar sobre estos hechos. Esto deberá ser recogido en un material escrito, pero hoy no podemos ver todo este detalle, es quizá una manera de poder visualizar cómo se dieron esos hechos.

Menciono este tipo de acontecimientos para entender, en su justa medida, el clima emocional y político en que se negoció el Pacto de Ochomogo, la salida de Manuel Mora y Carmen Lyra, y el esfuerzo titánico para deponer las armas en una coyuntura en la que el presidente Teodoro Picado había capitulado y los aliados entregaron las mejores armas a Somoza, como bien se conoce. En esa situación operativa estratégica, debe añadirse que Somoza ya había invadido a Costa Rica. Se iniciaba la Guerra Fría.

Dentro de un análisis objetivo hay que destacar los resultados del Pacto de Ochomogo, firmado en la embajada de México en Costa Rica, el cual se pactó en los siguientes términos:

1. Concluir la guerra y evitar una batalla por San José.

2. Evitar la invasión externa que ya estaba en curso con tropas de Somoza en San Carlos y la posibilidad real de una intervención de tropas norteamericanas desde la Zona del Canal.

3. Mantener las grandes conquistas sociales logradas gracias a la alianza entre el Partido Comunista, la Iglesia Católica y el gobierno del Dr. Calderón Guardia.

4. Mantener la legalidad de las organizaciones de masas y del Partido Comunista, que ya entonces había cambiado el nombre de Partido Comunista por el de Vanguardia Popular.

Gracias a este pacto no solo se respetaron las conquistas sociales, sino que se ampliaron. Se irrespetó la legalidad del Partido Comunista y de sus organizaciones de masas, principalmente los sindicatos.

El Partido Comunista fue ilegalizado por las presiones externas del Departamento de Estado. Ahora sabemos que el documento fotografiado en ciudad de Panamá a Manuel Mora, cuya copia fue localizada en el archivo de don Vicente Lombardo Toledano aquí en México, disparó una feroz campaña contra el Partido Comunista. 
Hubo medidas represivas de muy ingrata memoria que implicaron cárcel, allanamientos, golpizas y asesinatos como el del Codo del Diablo. La legalidad plena que vino a sellar el cumplimiento completo del Pacto se dio solo con la derogatoria del párrafo segundo del Artículo 98 de la Constitución, para lo cual don José Figueres Ferrer hizo un esfuerzo importante al cerrar el acuerdo completo del Pacto. Esa conquista, por la cual el Partido Comunista luchó por más de treinta años, se produjo en el gobierno de don Daniel Oduber.

No fue fácil para Don Pepe enfrentarse a los sectores que dentro de su propio ejército luchaban por derogar todas las grandes conquistas sociales. Con estos esfuerzos se relaciona incluso el intento de golpe de estado que dirigió Cardona por encargo de las fuerzas incontrastables en 1949, conocido como el Cordonazo.

El anticomunismo se convirtió en un instrumento central del utillaje sicológico utilizado por los sectores políticos dominantes en el país y sirvió de base al andamiaje que propuso la ilegalización y persecución de los comunistas después del cese de hostilidades, como un recurso descalificador, que prevalece hoy como parte del imaginario nacional.

La persecución sistemática de los comunistas que siguió al Pacto de Ochomogo produjo, entre otros fenómenos, un exilio costarricense a México y Venezuela, principalmente. La reconstrucción de este periodo requiere mayores estudios e investigaciones; con el apoyo de la academia mexicana se ha avanzado, pero tenemos pendientes los archivos de la inteligencia mexicana de los años 40 y 50, los cuales deben de estar desclasificados, y esto nos daría una mejor idea de qué hicieron esos hombres y mujeres.

En los años 80, don Pepe y Manuel Mora hacen un esfuerzo muy importante, cuyo objetivo era evitar una intervención militar de los Estados Unidos en Nicaragua y lograr acuerdos de paz que evitaran el baño de sangre en El Salvador y Guatemala, principalmente. Tanto el conflicto de El Salvador como el de Guatemala concluyeron con acuerdos por todos conocidos después de muchos años de guerra que dejaron inmensos daños materiales y, lo más grave, con bajas humanas enormes. Hay que señalar que las fuerzas tenebrosas de la guerra que animaban al gobierno de Reagan en los Estados Unidos, jugaron un papel muy activo para hacerlo fracasar.

En ese esfuerzo, Manuel Mora y José Figueres Ferrer se reunieron con el comandante Fidel Castro Ruz, y desarrollaron negociaciones para intentar la pacificación del área, las que fueron intensamente torpedeadas por fuerzas tenebrosas que más bien querían mantener la guerra en la región e incluso ampliarla. Parte de esa maniobra contra la paz fue el allanamiento de la casa de Mora y la colocación de una bomba que debía destruir el avión de Copa en que viajaría Manuel Mora con don José Figueres. Según el relato de Mora, cuando el avión cargado de pasajeros iniciaba las maniobras para el viaje, una unidad operativa de la seguridad del Estado de Nicaragua lo detuvo, y extrajo de la zona de carga una maleta que detonó cuando se aproximaba la unidad al edificio de la terminal aérea. Este hecho es parte de una historia 
desconocida que deberá ser investigada y escrita con profundidad y que sumó esfuerzos por buscar la paz en el área.

El "comunismo a la tica" contribuyó a la transformación del agotado Estado Liberal, rescatando sus aspectos positivos, pero dando paso al nacimiento del Estado Social de Derecho en Costa Rica, también llamado Estado de Bienestar. La creación de la Universidad de Costa Rica, de la Caja Costarricense del Seguro Social, la promulgación de las Garantías Sociales, el Código de Trabajo y la Ley de Casas Baratas; son parte de las raíces sólidas del Estado costarricense, que subsisten hoy día a pesar de los embates neoliberales y sus procesos de privatización durante los últimos treinta años.

\section{Referencias}

Aguilar Bulgarelli, Oscar. Costa Rica y sus Hechos Politicos de 1948. San José: Editorial Costa Rica, 1969.

Díaz Arias, David. Reforma sin alianza, discursos transformados. 2003.

Cerdas Mora, Jaime. La otra vanguardia, Editorial Universidad Estatal a Distancia, 1993.

Mora Valverde, Manuel. Discursos. San José: Editorial Pablo Presbere, 1979.

Oliva, Mario. Movimientos Sociales de Costa Rica. San José: Editorial Universidad Estatal a Distancia, 1997.

Temas de Nuestra América (N 33), 2017. Exilio y presencia: Costa Rica México en el Siglo $X X$. Heredia: Editorial Universidad Nacional de Costa Rica. 
Señor Llc.don Manuel Mora Valverde

Secretarlo General del Partldo

Vanguar d1a Popular:

Pte.

Muy sefior mios

Al finalizar el arreglo promovido por el serior Presidento P1crdo para dar fin a la presente $g$ uorrá $c 1711,01$ señor don Jos 6 F1 ga eres, Comendante Jefe del Ejerci to de L1beraci on Nac1onal, me ha aut or 1zado par a ponior on su conoclmien to 10 siguiente:

Bl Estado Mayor del Ejerclto de Liberacion Nacional no ha querido pertialpar on la constitucion del Goblerno provialonal que estara a cargo del Ingeniero don Santas Loon Herrere, porque no qulere ningun contacto politico con el calêeronimo: Por lo tanto, ese Goblerno deberá ser opor tan mente rearganizado para que on 61 podamos temer nosotros la perticipacion que nos corresponde?: Pero desde ahor a, pod emos asegurar a ustedes 10 sigutentes que la cartera de Soguri dad Public s se mentendra a cargo del Lic.don Miguel Brenes Gutierrez on qulenes ustedes tienen confl anza; y que la secretar ia de Traho jo, si no se mantleme en manos del seriar Brenes se dara un ciudadano que sea ambo de su Partico el cual sera debidamente consultado.Los otros puestos del Gabinete que sea prec1so sustituir ser an oevo pados por personas de mentalidad progresist a de manera que ei nuevo coblerno sea una garantla real par a la c lase trab ajador a J para todo el pueblo\%

Ten go Instrucciones de hac orle, saber, ademas, Io 1 igulente 
que como nuestro proposito os revolucionar las formas do v1da del pais mal ante Ia promalgacion de un a Constitucion modern $a$, nuestra decision es que Inmedatamente sea c anvoc ada la Const1. tuyente.queremo que en la elqboracion de la nueva carta cons titucional Interveng an ustedes y queremos tamblen $q$ w ustedes tengan participacion act1 va on la cons 1 tuyent a misma.

Nosotros no constitu1mos un movimiento reaccionar $10 \mathrm{nl}$ abrigamos prefulc1 os contra ustedes.Par ol contrar 1o, cons 1d eramos que no se justifice el choque sangriento que se esta llevando a cabo de fuerzas de us tedes y nuestras si perfectamen. te podriamos, en una calsboracion honrada $y$ tac1ta, real1zar los 1deales mas sent1dos por nuestra c lase trabajador a y por nuestro preblo:

Por razones de orden politico, que no escaparan a la comprension suya,le ruego tener este documento como pr 1vado.

De Ud. atentament $\theta_{\text {, }}$

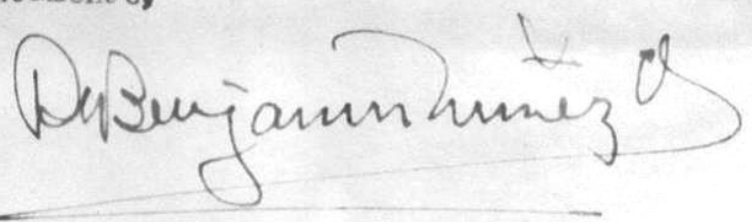

P.D.

Adjunto a la prensente, s1guiendo instrucciones del señor Flgueres, un pliego que contiene una serie do garantias de caracter politico y socilal que seguramente satis faran a su partido.- 
E1 "Bjorct to de Liberación Nacional" presente al Partido Vanguardia Popular parte de su progreme social de gobierno, cuya reaización promete u todos los trabajadores de Coste Rica.

1. - Las Garant1as Sociales no solo serân respetadas sino tambín reelizadas en forma afective on todos aquellos aspectos en que no 10 han aldo todarfa.

2. - Kl Codigo de Trabajo no suerirá modificación negativa a 108 intereses de 108 trabajadores; por el contrario, serd perfeccionado a favor de 108 mi emos. Intre esas mejoras consideramos enencial al reconocimiento del derecho de huelga para todos los trabajadores del pals.

3. - Observando el prinolp1o de libertad de organizacion para 1a clase trabajadora, se respetarín y darén garantias para la existenc1a y actividades de las Contrales Sindicales existentes on el pals, 1a Rorum Novarum y la CTCR (Confederación de Trabajadores de Costa R1ca). El Goblerno les garant1zará apoyo económico y moral sin preferencias para ninguna de ellas.

4. - A I in de der mayor seguridad al trabajador desde la cuna has ta la tumba, el sistema de seguros sociales no sblo serd respetado sino estructurado en forma tal que todos 108 riesgos profesionales incluyendo 108 aceldentes de trabajo queden incorporados a un orga nlemo f́nfeo. Se procuraré de manera inmediata extender 108 benef1c10s de la seguridad social a todos 108 trabajadares y a todo al pafs.

5. - Será preocupación Inmediata la intensificación en la ejecuc1ón de un plan de viviendas baratas para todos 108 trabajadores de la cluded $y$ del eampo.

6. - Haciendo 108 eafuerzos que sean necesarios en el campo de la produceión de artfeulos de consumo popular $y$ en el control de su distribucion, se procurará asegurar la alimentación adecuada pa ra toda la población.

7. - Se guardará absoluto y efectivo respeto al sistema democrat1co republicano asegurando y respetando las libertades de pensa-miento, de conclencla, de pelabra, de reunión y de organización a todos los Partidos polfticos que existan o pueden establecerse en el pals.

8. - In Limpuesto sobre la Renta no s610 no serA suprimido, sino que se 1o darén bases técnicas más serias elln, asegurando además, dentro de la honestidad administrativa, su aplicación a la solucion 
- Hoja número 2 -

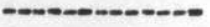

de las necesidades fundamentales del pueblo.

9. - Se proceder a robustecer y ejecutar un programa de distribuc $16 n$ de tierras complementado con los medios crediticios y técn1$\cos$ que el Bstado pueda aportar.

10. - Las familia de todas las victimas de la guerra c1vil y las victimas incapacitadas, recib1rên, sin distinc1on de partidos pollt1cos, indemnizaciones adecuadas. Bl Goblerno hara las gestiones ne cesarias para que todos los trabajadores que hayan participado en 1a guerra, sin distinción de pertidos polfticos, puedan volver a sus trabajos sin que 108 contratos de trabajo respectivos puedan conside rarse rotos.

SAN JOSE, $v_{\bullet} R_{\bullet}$ diez y nueve de abril de m1l novecientos cuarenta $y$ ocho.



